\title{
DIFERENÇAS DE CULTURA ENTRE INSTITUIÇÕES DE ENSINO SUPERIOR PÚBLICO E PRIVADO - UM ESTUDO DE CASO
}

\author{
Aristides Isidoro Ferreira ${ }^{1}$ \\ Manuela Magalhães Hill ${ }^{2}$
}

Resumo: A presente investigação tem por objectivo verificar se existem diferenças de cultura entre duas instituições de ensino superior: uma do sector privado e outra do sector público. Procura-se verificar uma maior tendência das universidades privadas por uma abordagem no Modelo de Regulação por Mecanismos de Mercado (Correia, Amaral \& Magalhães, 2002). Espera-se, neste sentido, que a instituição privada possua uma orientação de cultura mais vocacionada para o exterior e a universidade pública, possuindo maior dependência do Estado, assuma uma maior propensão para os processos internos.

Este estudo integrou uma metodologia quantitativa, com a utilização de um questionário baseado no Modelo dos Valores Contrastantes de Quinn e McGrath (1985). O questionário foi devidamente adaptado para medir a dimensão cultura escolar. Por outro lado, recorreu-se a uma metodologia qualitativa, com a utilização de um guião de entrevista estruturado, baseado nos modelos teóricos de cultura organizacional e escolar (Bergquist, 1992; Quinn, 1991; Schein, 1992; Torres, 1997). O questionário foi aplicado a 62 colaboradores da universidade pública e 52 colaboradores do sector privado. Aplicou-se também um conjunto de 10 entrevistas, na instituição de ensino superior público, e 8 entrevistas, na instituição de ensino superior privado.

Os resultados revelaram valores médios de cultura superiores na universidade privada, contudo, as diferenças significativas $(p<0,05)$ demonstraram uma maior orientação para o mercado, enquanto padrão de cultura marcadamente assumido no ensino superior privado. $\mathrm{O}$ estudo revelou ainda uma maior preocupação burocrática $(p<0,05)$ na universidade privada, com referência às regras e padrões de comunicação formais.

A universidade pública denotou, por intermédio da análise discriminante, uma maior aproximação a culturas do tipo Clã. Esta medida foi interpretada pela forma informal com que os diversos agentes escolares interagem entre si. Verificou-se

\footnotetext{
${ }^{1}$ Universidade Lusíada de Lisboa. A correspondência relativa a este artigo deverá ser endereçada a Aristides Isidoro Ferreira, Departamento de Psicologia, Universidade Lusíada de Lisboa, Rua da Junqueira 188/198, 1349-01 Lisboa, e-mail: aristides@lis.ulusiada.pt

2 Instituto Superior de Ciências do Trabalho e da Empresa.
}

PSICOLOGIA, Vol. XXI (1), 2007, Edições Colibri, Lisboa, pp. 7-26. 
ainda alguma intenção das chefias de ambas as instituições de ensino superior em evoluir para padrões de flexibilização nos procedimentos de desenvolvimento de novos produtos de ensino.

Palavras-chave: cultura, ensino superior, público e privado.

Culture differences between private and public higher education institutions - A case study (Abstract): The aim of this study is to demonstrate the culture differences between two higher education institutions: public and private. According to the Model of Regulation for Market Mechanisms (Correia, Amaral \& Magalhães, 2002), it is expected that private universities possess a more external oriented culture than public universities, which have a larger dependence on the State.

This research project integrated a quantitative methodology with the use of a questionnaire, based on the Contrasting Values Model (Quinn \& McGrath, 1985), which was later adapted to measure school culture dimensions. A qualitative methodology was also used in this study with a structured interview, based on the theoretical models of organizational and school culture (Bergquist, 1992; Quinn, 1991; Schein, 1992; Torres, 1997). The questionnaire was given to 62 employees of the public institution and 52 collaborators from the private sector. A total of 10 interviews were also applied to the public university and 8 interviews to the private institution.

The results revealed higher culture values in the private university. However, the significant differences $(p<0,05)$ reflected a larger Market Culture orientation. The study also displayed a larger Bureaucratic Culture $(p<0,05)$ in the private university, with reference to the rules and formal communication patterns. The public university denoted, through the discriminating analysis, a larger approximation to Clan Cultures - a result which was interpreted by the informal relationship that was depicted amongst the interviewees. Lastly, both public and private directing committees of the higher education institutions showed interest in developing flexibility patterns in the creation and innovation of new courses or scholarship programmes.

Key-words: culture, higher education, public and private.

\section{Introdução}

A cultura tem sido uma das dimensões mais estudadas em contexto organizacional (Bollinger \& Hofstede, 1987; Denison, 1990; Hofstede, 1991, 1994, 1997; Hofstede \& Peterson, 2000; Lopes \& Reto, 1990; Neves, 2000; Parker, 2000; Quinn, 1991; Schein, 1988, 1992, 1994, 1996, 1999, 2000). O fenómeno de cultura organizacional surge, muitas vezes, associa- 
do à estratégia (Ramos, 1993) ou ao desempenho organizacional (Gomes, 2000; Major, 2000; Neves, 2000; Quinn, 1991; Wilderom \& Glunk, 2000). Existem, contudo, poucos estudos que retratem o fenómeno de cultura organizacional em instituições de ensino (Bergquist, 1992; Chorão, 1992; Dill, 1997; Geiger, 1996; Gomes, 1993; Torres, 1997).

Esta investigação procura compreender o fenómeno da variável cultura no contexto das instituições universitárias, uma realidade que apresenta algumas particularidades que a diferenciam dos restantes estudos de cultura realizados em organizações que não instituições de ensino (Bergquist, 1992). Perante uma actual conjuntura de dificuldades no ensino universitário em Portugal, torna-se necessário compreender as razões responsáveis por respostas eficazes no actual sistema de ensino superior, para assegurar critérios de competitividade e de sobrevivência face à concorrência. Na realidade, assistimos, cada vez mais, à imposição de barreiras às instituições de ensino superior e que se traduzem, nalguns casos, na redução da procura de alunos (motivada, entre outros factores, pela redução da taxa de natalidade), maior concorrência entre universidades, abertura de fronteiras e concorrência internacional. Para além disso, esse fenómeno da globalização e abertura de mercados provocou um aumento das exigências e consequente levantamento de factores de convergência face aos índices de excelência das universidades europeias e norte-americanas. Como referem Correia, Amaral e Magalhães (2002), a diversidade e a diversificação dos sistemas de ensino superior conduzem, necessariamente, à mudança para um novo paradigma universitário, assente numa cultura orientada para o mercado e que reflicta uma base assente no desenvolvimento do conhecimento tecnológico e inovação. Cabe às universidades modernas responderem às exigências da sociedade.

Em Portugal, o actual sistema de ensino depara-se com duas realidades distintas: o ensino superior público e privado. O último, tendo surgido mais recentemente no actual panorama do ensino superior, debate-se com algumas dificuldades de afirmação, uma vez que está mais dependente do financiamento proveniente das propinas dos alunos. No caso do sector público, a lei de autonomia das universidades não desvincula as universidades públicas do Estado, já que este continua a ser o seu principal financiador.

O presente trabalho tem como objectivo a investigação da cultura organizacional em duas instituições de ensino: uma de ensino superior público e outra de ensino superior privado. Pretende-se estudar se o tipo de modalidade de ensino (estatal ou privada) altera os valores dominantes numa universidade, sendo que, na sua maioria, os actores escolares prevalecem os mesmos (professores, alunos, funcionários). É ainda intuito desta invêstigação averiguar da possível existência de subculturas dentro das instituições de ensino estudadas. 


\section{O Efeito Propriedade no Ensino}

Correia et al. (2002) referem que as instituições de ensino superior, enquanto organizações, tomam as suas decisões, de acordo com as políticas internas em relação ao meio em que actuam. Desta forma, quanto maior a influência normativa do Estado ao nível do ensino superior, tanto maior a diversidade do sistema de ensino e as restrições à inovação e criatividade (Correia et al., 2002).

O modelo de controlo pelo Estado resulta das exigências dos serviços estatais para dotar os seus postos de trabalho e, consequentemente, enriquecer/ qualificar os recursos humanos, visando um melhor acompanhamento no desenvolvimento tecnológico do Governo Central.

Nos últimos 30 anos, verificou-se uma mudança do Modelo de Controlo pelo Estado, para um Modelo de Auto-Regulação e Supervisão pelo Estado. As razões assentam, sobretudo, numa enorme incapacidade das instituições em se reformarem e em darem resposta a uma envolvente em constante mudança na procura de um conjunto de respostas cada vez mais exigentes e diversificadas (Correia et al., 2002). No fundo, estamos perante uma situação em que as instituições são expostas ao julgamento do controlo externo (Pesqueux, 2003).

No entanto, é de salientar que, quando se fala na autonomia que aos poucos vai sendo adquirida, estamos longe de evocar a independência do ensino, já que o Estado não abdica de alguns mecanismos de regulação das universidades. Um exemplo notório é a aprovação dos cursos e disciplinas cuja regularização é sempre determinada, em última instância, pelo Estado.

À medida que a autonomia se desenvolve, maior é a aproximação a uma lógica não de regulação pelo governo, mas de regulação pelo mercado, em que este procura organizar a troca de bens e serviços (que, neste caso, é o ensino), tendo como base um preço e não uma tradição ou mesmo escolha política (Dill, 1997).

A orientação para o mercado torna-se uma necessidade quando os recursos são escassos, assumindo-se, desta forma, o mercado como uma força motriz para a diversificação das instituições de ensino superior e o aumento do papel da competitividade (Geiger, 1996).

$\mathrm{O}$ mercado faz ainda com que as universidades compitam entre si, criando um sistema diversificado, marcado pela estratificação que separa as universidades de elite das universidades que vão sentindo algumas dificuldades em impor a sua posição no mercado.

Em suma, parece importante haver uma regulação forte por parte do Estado, como elemento facilitador da diversificação e controlo do sistema de ensino, no entanto, com alguma influência do mercado como forma de aumentar os índices de competitividade e, naturalmente, optimizar as refe- 
rências de qualidade, eficiência e eficácia no ensino. Esse mecanismo de regulação pelo Estado pode, de alguma forma, regular a cultura das instituições de ensino superior e, assim, influenciar toda a sua dinâmica de funcionamento. Desta forma, seguir-se-á uma breve incursão à teoria do Modelo dos Valores Contrastantes que, de alguma forma, procura integrar as organizações nas várias facetas de cultura definidas pelo modelo (Quinn, 1991).

\section{Modelo dos Valores Contrastantes de Quinn e McGrath (1985)}

Quinn e McGrath (1985) criaram uma tipologia da cultura das organizações (Modelo dos Valores Contrastantes) que teve a sua origem num conjunto de estudos empíricos e investigações. Através da análise estatística dos resultados de múltiplos estudos, conseguiram-se identificar 4 clusters distintos que resultam do cruzamento de duas dimensões com pólos opôstos, de flexibilidade versus estabilidade e de internalidade versus externalidade (Quinn \& McGrath, 1985). Estes 4 clusters representam quadrantes de indicadores (critérios) de eficácia organizacional, os quais reflectem aquilo que as pessoas valorizam acerca do desempenho organizacional.

Assim, a parte superior esquerda do quadrante identifica os valores da internalidade e flexibilidade, que caracteriza uma cultura Clã. O quadrante inferior direito descreve valores marcados por uma dimensão de externalidade e estabilidade (controlo), que caracteriza uma cultura de mercado. Da mesma forma, o quadrante superior direito reporta-se aos factores de externalidade e flexibilidade associados a uma cultura de Adhocracia, enquanto que o quadrante inferior esquerdo reenvia para a internalidade e valor de estabilidade que caracterizam uma cultura de Burocracia

A cultura Burocrática (ou Hierárquica) é influenciada pela gestão, no sentido da formalização das estruturas e dos locais de trabalho. Desta forma, o lema deste tipo de organizações é a estabilidade, previsibilidade e eficiência. O enfoque da gestão vai todo no sentido do cálculo, medida, documentação e gestão da informação. Os colaboradores possuem regras bem definidas e estão predispostos a seguir essas linhas orientadoras, através de comportamentos que se pautam, essencialmente, pela estabilidade e previsibilidade. A maior recompensa do trabalho é, de facto, a segurança. Dos líderes são ainda esperados dois papéis distintos: de monitorização e de coordenação de equipas (Quinn, 1991: p. 39).

No que concerne à cultura de mercado, esta refere-se às instituições que funcionam de acordo com uma lógica de mercado. São vocacionalmente orientadas para a envolvente externa e é nesse sentido que orientam todas as funções internas. Focam-se nas acções com o meio externo, incluindo clientes, fornecedores, accionistas e outros agentes que interferem directamente com os resultados da organização. Procuram-se vantagens com- 
petitivas, através das transacções (trocas, vendas, contratos) visando a obtenção do lucro, os resultados da linha de produção, prospecção de novos nichos de mercado, segurança e satisfação dos clientes.

A designação da cultura de Clã está, muitas vezes, associada a organizações de tipo familiar. Caracterizam-se, então, pela partilha de valores e objectivos, coesão, participação e colectivismo. As instituições que possuem este tipo de cultura defendem o trabalho em equipa e os programas de envolvimento.

Por último, a cultura de Adhocracia é o tipo de cultura que se adequa ao género de ambientes turbulentos, na medida em que se caracterizam por organizações onde a tónica assenta no decréscimo dos ciclos de vida dos produtos, premissas de cultura que defendem a inovação e as iniciativas de pioneirismo enquanto factores que levam ao sucesso. O princípio da gestão vai no sentido da criatividade e assume que a adaptação e a aposta no risco leva a novos recursos de lucros, enfatizando uma visão criativa do futuro, anarquia organizada e disciplina.

Desta forma, acedendo à cultura organizacional, consegue-se analisar a organização como um todo. Pode-se, então, considerar que o modelo teórico foi constituído para estruturar a cultura organizacional em partições distintas, não sendo de todo um fenómeno compreensivo e que abarque toda a problemática do fenómeno organizacional (Cameron \& Quinn, 1999; Schein, 1999, 2000).

Apesar da discordância metodológica e dos diversos pontos de vista encontrados acerca de algumas teorias que integram a dinâmica da cultura das organizações, interessa para enquadramento do estudo, compreender a importância da cultura organizacional numa perspectiva algo particular: a realidade escolar.

\section{Cultura escolar}

As instituições de ensino incorporam o mesmo tipo de teorias e modelos que as restantes organizações; no fundo, o que as distingue é a missão que as caracteriza. Essa missão dá origem a culturas e climas muito específicos, face aos vários modelos organizacionais existentes (Silva, 1996).

Para Torres (1997), a abordagem da cultura organizacional escolar reenvia para um quadro teórico-conceptual de referência ao contexto empresarial, com algumas diferenças, na medida em que estamos perante uma organização de âmbito educativo, que prescreve valores e padrões marcadamente distintos. Não obstante essa distinção, até aos anos 70, essas diferenças assumiam-se como sendo algo difusas.

$\mathrm{O}$ actual modelo de gestão das escolas tem origem numa cultura organizacional de mudança e desenvolvimento que se gerou entre alunos, pro- 
fessores e funcionários, em profunda contestação com o tipo de ensino vigente, nas escolas do tipo hierárquico e autocrático que marcava o ensino há algumas décadas atrás.

Torres (1997) desenvolveu uma abordagem aos factores exógenos e endógenos à instituição escolar. Os primeiros são exteriores à escola enquanto organização, os segundos, sendo internos, intervêm directamente, já que contemplam os agentes sociais que fazem parte da escola.

De acordo com o modelo, descobre-se que 4 factores concorrem entre si para o desenvolvimento da cultura organizacional escolar. Assim, temos nos factores internos uma dimensão mais social e que encerra em si um processo de socialização intra-organizacional (1). Numa tónica menos social e mais organizacional, temos o factor de inserção organizacional (2). Atendendo ao factores externos ou exógenos, pode-se considerar um quadrante que reflecte uma socialização extra-organizacional (3) que contrasta com o quadrante de vocação organizacional que pauta os percursos profissionais e escolares (4).

Associadas ao quadrante de socialização intra-organizacional, temos variáveis sociais como frequência e tipo de convívio, relações entre colegas, formalismo nas relações. No que concerne ao quadrante da inserção organizacional, as variáveis do tipo organizacional identificam o grupo disciplinar dos indivíduos, tempos de serviço nas escolas, tipo de categoria dos professores (quadro, fora dos quadros) e tipo de cargos e funções desempenhadas na escola. Nos quadrantes associados aos factores externos, e no que diz respeito à socialização extra-organizacional, existem variáveis sociais importantes a ter em conta, nomeadamente, o sexo, idade, residência e classe social de origem dos agentes escolares. Já o quadrante dos percursos prófissionais e escolar, numa tónica marcadamente organizacional, prescreve variáveis socioprofissionais como categoria profissional, habilitações académicas, instituição onde foram graduados os professores e número/ experiência de escolas em que o docente leccionou.

Numa outra abordagem menos orientada para a génese dos processos de cultura, mas mais vocacionada para a classificação dos processos de cultura no ensino superior, Bergquist (1992) propõe um modelo para compreender a cultura nas instituições de ensino superior. Neste sentido, preconiza a existência de culturas Colegiais, onde se assiste à criação de subculturas dentro das universidades. Por outro lado, quando os processos de decisão estão centralizados e existe pouca descentralização, pode-se considerar a existência de uma cultura de Gestão, que marca uma dependência nos diversos órgãos decisores. As universidades apresentam ainda uma cultura de Desemvolvimento, quando existe uma procura no desenvolvimento dos seus recursos humanos, facto que poderá, em alguns casos, misturar-se com uma 
cultura de Negociação, na qual se procura um equilíbrio na distribuição dos recursos existentes.

Em jeito de conclusão, estes pressupostos teóricos permitem-nos inferir que, de alguma forma, todos os actores escolares (professores, alunos, funcionários e encarregados de educação) interferem e influenciam a cultura escolar através do processo de sociabilização organizacional e profissional, comportamentos, valores e crenças partilhadas. Sendo assim, e para efeitos de estudo, colocam-se as seguintes hipóteses:

Hipótese 1: Verificando que existe uma maior tendência das universidades privadas por uma abordagem no Modelo de Regulação por Mecanismos de mercado, espera-se que a universidade privada possua uma orientação de cultura mais vocacionada para uma procura de competição face à envolvente e especial enfoque numa cultura de mercado (Quinn \& McGrath, 1985).

Hipótese 2: A universidade pública, possuindo maior dependência do Estado, tenderá a enveredar pela manutenção de um sistema tecnológico com maior orientação para os processos internos. Espera-se, portanto, neste caso, uma maior tendência para o modelo das relações humanas e integração nos processos internos.

\section{Método}

\section{Amostra e Procedimento}

O presente estudo incide sobre dois estabelecimentos de ensino superior universitário, um instituto público e uma universidade privada. $\mathrm{Na}$ escolha da amostra, procurou-se que ambas as instituições apresentassem características equivalentes. Neste propósito, as duas foram fundadas na década de 70 e apresentam uma matriz de ensino com cerca de 15 cursos na pública e 14 licenciaturas na privada. Os cursos estão integrados nas áreas das ciências sociais, ciências da gestão e ciências tecnológicas. Possuem ainda, em média, cada uma, cerca de 1000 alunos a frequentar as suas diversas licenciaturas.

Para a aplicação dos questionários pretendeu-se abranger o universo dos colaboradores não docentes que desempenham funções administrativas, técnicas e de direcção/gestão.

Assim sendo, na caracterização do universo (Quadro 1), temos, na instituição de ensino superior privado, 16 indivíduos que desempenham funções de chefia, 45 funcionários que desempenham funções de âmbito técnico e 67 colaboradores administrativos. Na instituição de ensino superior 
público, 62 funcionários pertencem aos quadros administrativos, 46 elementos possuem a categoria de técnico e 14 pessoas desenvolvem funções de direcção/gestão. No entanto, não foi possível o registo de todos os funcionários, uma vez que grande parte destes recusou o preenchimento do questionário, alegando motivos muito variados. Sendo assim, ainda se conseguiu recolher 50,8\% de respostas na instituição pública. Dos 62 respondentes na instituição de ensino superior público, 11 desempenham funções de direcção/gestão, 20 elementos pertencem a categorias associadas a funções técnicas e 29 pessoas pertencem aos quadros administrativos, os restantes 2 elementos não identificaram as suas funções. No que diz respeito à instituição de ensino superior privado, apenas se conseguiram 52 questionários (representam $40,6 \%$ do total dos colaboradores), distribuídos pelas seguintes categorias de funções: 6 elementos pertencentes aos quadros de direcção/gestão, 16 colaboradores em funções técnicas e por último, 29 funcionários integrãdos nos quadros administrativos. Neste caso, apenas um elemento não identificou a função a que pertence. Dos indivíduos inquiridos no instituto superior público, $75,4 \%$ pertencem ao sexo feminino. No caso da universidade privada, 32 inquiridos pertencem ao sexo feminino, o que corresponde a $61,5 \%$ da amostra.

Quadro 1. Relação entre o total de colaboradores e o número de respostas

\begin{tabular}{lcccc}
\hline & \multicolumn{2}{c}{ Público } & \multicolumn{2}{c}{ Privado } \\
\cline { 2 - 5 } & Universo & N. $^{\mathbf{0}}$ de Respondentes & Universo & N. $^{\mathbf{0}}$ de Respondentes \\
\hline Direcção/ Gestão & 14 & $11(78,6 \%)$ & 16 & $6(37,5 \%)$ \\
Técnicas & 46 & $20(43,5 \%)$ & 45 & $16(35,6 \%)$ \\
Administrativas & 62 & $29(46,8 \%)$ & 67 & $29(43,3 \%)$ \\
Total & 122 & $62(50,8 \%)$ & 128 & $52(40,6 \%)$ \\
\hline
\end{tabular}

Nota: O total inclui também os elementos que não mencionaram a função a que pertenciam

A idade e antiguidade média dos colaboradores inquiridos no instituto de ensino superior público são de 38 anos e de 10 anos, respectivamente. Por seu lado, no instituto de ensino superior privado, embora a idade média dos seus colaboradores seja também os 38 anos, a antiguidade é ligeiramente superior, fixando-se nos 12 anos.

Para a realização das entrevistas, procurou-se entrevistar pessoas que desempenhassem funções no topo da hierarquia das duas instituições de 
ensino superior estudadas. No que diz respeito ao instituto público, entrevistaram-se 10 indivíduos; no caso da universidade privada, entrevistaram-se 8 elementos de chefia/direcção.

As entrevistas foram registadas em registo magnético, tiveram um carácter presencial e demoraram em média 1 hora e 20 minutos. De seguida, recorreu-se ao auxílio do software MAXQDA para classificação do conteúdo das entrevistas, numa matriz de categorias que integrou dimensões relacionadas com os níveis de cultura defendidos por Schein (Artefactos, Valores Expostos e Pressupostos Básicos), as dimensões dos valores de cultura de Adhocracia, mercado, Burocracia e Clã (Quinn \& McGrath, 1985), os factores internos e externos de cultura (Torres, 1997) e ainda as dimensões de cultura Colegial, Desenvolvimento, Gestão e de Negociação propostas por Bergquist (1992). Para facilitar o processo de análise do conteúdo das entrevistas, procedeu-se ainda a uma operacionalização dos constructos em sub-categorias mais específicas, de acordo com um dos métodos propostos por Bardin (2004).

\section{Instrumentos}

\section{Entrevista de Cultura Escolar}

A metodologia qualitativa consistiu numa entrevista semiestruturada de cultura adaptada ao contexto do ensino superior. Procurou-se desenvolver um guião que abarcasse as dimensões de cultura retratadas ao longo do corpo teórico. Da mesma forma, a construção do guião da entrevista teve por base os guiões de entrevista desenvolvidos por autores como Schein (1992) e Quinn (1988). A estrutura desses guiões originais obedece, no entanto, a uma formatação marcadamente empresarial. Desta forma, houve necessidade de reestruturar alguns conceitos, de forma a adaptar os conteúdos ao contexto de Cultura Escolar.

O guião utilizado é constituído por questões provenientes da Entrevista do Tipo Estruturado (Quinn, 1988), baseada na Teoria dos Modelos Contrastantes de Quinn e McGrath (1985). Integrou ainda os tópicos de entrevista defendidos por Schein (1992) para analisar os três níveis de cultura: Pressupostos-Base, Valores Expostos e Artefactos. Foram ainda desenvolvidas questões para aprofundar as dimensões de Cultura Escolar preconizadas por Torres (1997) e que contemplam os factores externos e internos à Cultura Escolar. Por último, o guião procurou identificar os 4 tipos de cultura propostos por Bergquist (1992) e que se inserem nas dimensões de cultura Colegial, cultura de Desenvolvimento, Gestão e Negociação. 


\section{Questionário de Cultura Organizacional}

Foi aplicado o questionário para analisar a cultura organizacional de Robert E. Quinn (1988). Este questionário mede as dimensões de cultura, tendo por base a teoria dos valores contrastantes. Na sua versão original, o questionário apresenta a designação de Organizational Culture Assessment Instrument (OCAI). É constituído por 24 questões que medem as dimensões de cultura de Clã (itens 1, 5, 9,13,17 e 21), Adhocrática (itens 2, 6, 10,14, 18 e 22), Burocrática (itens 3, 7, 11, 15, 19 e 23) e de Mercado (itens 4, 8, $12,16,20$ e 24). A forma de resposta inicialmente adoptada preconiza que os sujeitos distribuam 100 pontos pelas diversas alternativas. O autor da escala também considera a possibilidade de utilização de uma escala de Likert de 7 pontos, na qual os inquiridos respondem a cada questão, tendo em conta que 1 corresponde a "muito raramente" e 7 "muito frequentemente". Atendendo às baixas qualificações dos inquiridos, decidiu-se optar pela segunda fórmula de respostas.

No que concerne às qualidades métricas da escala, esta apresenta índices de consistência interna elevados. Um estudo realizado por Zammuto e Kakower (1991; cit. por Cameron \& Quinn, 1999), a uma amostra de 1300 elementos de instituições de ensino superior, revelaram índices de 0,82 para Clã, 0,83 para Adhocracia, 0,67 para Burocracia e 0,78 para Mercado. Estes elevados resultados atestam a boa fidelidade da escala. Também Cameron e Freeman (1991; cit. por Cameron \& Quinn, 1999) confirmaram a validade da escala num total de 3406 indivíduos de instituições de ensino secundário e universitário dos Estados Unidos da América.

\section{Resultados}

Para análise das diferenças culturais nas instituições de ensino superior, optou-se por uma abordagem quantitativa e qualitativa. Neste sentido, através do package estatístico do SPSS 12.0 recorreu-se à análise discriminante, de forma a verificar quais os padrões de cultura que "melhor" discriminam os dois tipos de instituição de ensino superior.

Da análise discriminante através do método stepwise resultou então uma função canónica com um valor próprio de 0,138. Este baixo valor explica alguma proximidade dos centróides referentes às instituições de ensino superior em estudo, ou seja, é pequena a variação entre as duas instituições explicada pela função discriminante. O quadrado da correlação canónica apresentado no Quadro 2 indica que, aproximadamente, $12 \%$ da variância da discriminação canónica é explicada pelas instituições de ensino superior público e privado estudadas (valor bastante reduzido, embora significativo para $p<0,01$ ). O valor de Wilk's Lambda de 0,879 demonstra 
que cerca de $87,9 \%$ da variância não é explicada pela diferença entre as instituições de ensino superior referidas no estudo.

Quadro 2. Resultados da Análise Discriminante

\begin{tabular}{llllllll}
\hline Função & Eigenvalue & \% de variância & $\begin{array}{l}\text { Correlação } \\
\text { Canónica }\end{array}$ & $\begin{array}{l}\text { Wilks' } \\
\text { Lambda }\end{array}$ & X & Df & Sig. \\
\hline 1 & 0,138 & 100 & 0,348 & 0,879 & 14,315 & 2 & 0,001 \\
\hline
\end{tabular}

Os dados reflectem os resultados da análise discriminante através do método stepwise e que permitiu a entrada de duas dimensões de cultura (cultura de Mercado e de Clã) para explicar 12\% da função discriminante.

Da análise das tabelas resultantes da matriz de estrutura e da função dos grupos centróides (Quadros 3 e 4), verifica-se que, quanto mais positivo, mais o indicador de cultura se aproxima da instituição de ensino superior privado. A dimensão de Mercado está mais próxima da instituição de ensino privado, seguindo-se todas as outras pela seguinte ordem de entrada: cultura de Mercado, Burocrática, Adhocrática e de Clã. No entanto, a cultura de Clã traz um contributo adicional para a função discriminante entre o privado e o público, uma vez que, estando próxima da instituição de ensino superior privado, é a dimensão que mais se aproxima da instituição de ensino superior público, nos $64,9 \%$ dos casos em análise.

Quadro 3. Matriz de Estrutura

\begin{tabular}{lc}
\hline & Função 1 \\
\hline Cultura de Mercado & 0,822 \\
Cultura Burocrática & 0,462 \\
Cultura Adhocrática & 0,284 \\
Cultura de Clã & 0,080 \\
\hline
\end{tabular}

Quadro 4. Função dos Grupos Centróides

\begin{tabular}{lc}
\hline Instituição & Função 1 \\
\hline Público & $-0,337$ \\
Privado & 0,402 \\
\hline
\end{tabular}


A matriz de classificação resultante da análise discriminante indica que $64 \%$ dos casos em análise foram bem classificados pelas duas variáveis utilizadas no método stepwise. É interessante referir que a aplicação da regressão logística ao mesmo grupo de dados confirma os resultados obtidos pela análise discriminante, classificando igualmente bem $64 \%$ dos casos analisados.

Constata-se, desta forma, que a cultura de Clã, embora estando mais próxima da instituição de ensino superior privado, é, de todas as dimensões, aquela que se aproxima mais da instituição de ensino superior público. Pelo contrário, a cultura de Mercado apresenta um maior destaque na instituição de ensino superior privado e, consequentemente, um maior distanciamento da outra instituição estudada.

Para confirmar a análise discriminante, efectuou-se uma análise estatística de $t$-test. Procurou-se encontrar diferenças significativas $(p<0,05)$ entre as duas instituições de ensino superior, no que diz respeito aos valores médios das diversas dimensões de cultura estudadas. Os resultados podem ser observados no Quadro 5.

Quadro 5. Diferenças de cultura entre colaboradores da instituição de ensino público e privado

\begin{tabular}{|c|c|c|c|c|c|c|}
\hline & & $N$ & Média & $D P$ & t-test & Sig. (2-tailed) \\
\hline \multirow{2}{*}{ Cultura de Clã } & Público & 62 & 3,867 & 1,009 & \multirow{2}{*}{$-0,316$} & \multirow{2}{*}{0,753} \\
\hline & Privado & 52 & 3,933 & 1,205 & & \\
\hline \multirow{2}{*}{ Cultura Adhocrática } & Público & 62 & 3,865 & 1,067 & \multirow{2}{*}{$-1,313$} & \multirow{2}{*}{0,192} \\
\hline & Privado & 52 & 4,144 & 1,199 & & \\
\hline \multirow{2}{*}{ Cultura Burocrática } & Público & 62 & 3,924 & 0,833 & \multirow{2}{*}{$-2,743$} & \multirow{2}{*}{$* 0,007$} \\
\hline & Privado & 52 & 4,403 & 1,029 & & \\
\hline \multirow{2}{*}{ Cultura de Mercado } & Público & 62 & 3,75 & 0,96 & \multirow{2}{*}{$-3,229$} & \multirow{2}{*}{$* 0,002$} \\
\hline & Privado & 52 & 4,344 & 0,997 & & \\
\hline
\end{tabular}

Nota: *sig $<0,01 ; D P .=$ Desvio Padrão

Os resultados demonstram a existência de diferenças significativas $(p<0,01)$ ao nível da cultura Burocrática e Cultura de Mercado. Sendo assim, a instituição de ensino superior privado possui uma cultura mais burocrática e orientada para o Mercado, do que a instituição de ensino superior público. 
De uma forma geral, os colaboradores do privado apresentam valores de cultura superiores aos dos funcionários do público, nas quatro dimensões de cultura estudadas.

Através da ANOVA, tentou-se ainda encontrar diferenças de cultura nas funções desempenhadas pelos funcionários que participaram no estudo. Sendo assim, não se verificaram diferenças significativas para os colaboradores da universidade privada. No que concerne ao sector público, verificaram-se diferenças significativas $(p<0,05)$, na medida em que os funcionários que desempenham funções de direcção/gestão apresentam maiores índices de cultura de Clã, Adhocrática e de Mercado que os colaboradores de funções técnicas. Ainda no que diz respeito à cultura de Mercado, os funcionários que desenvolvem funções técnicas possuem valores mais elevados desta cultura que os seus colegas administrativos.

Uma análise de clusters permitiu identificar os grupos com valores de cultura superiores em cada uma das instituições de ensino superior em estudo. Através do método Ward, procurou-se identificar 3 clusters distintos. Como se pode observar no Quadro 6, no caso do sector privado, obteve-se um cluster de 8 casos com valores de cultura muito elevados em todas as dimensões (superiores a 5 pontos, numa escala que pode assumir como valor máximo o número 7). No sector público, obteve-se um cluster mais representativo, com 29 casos, mas cujos valores, sendo elevados (superiores a 4), não chegam a ultrapassar a barreira das 5 unidades, tal como verificado no cluster do instituto de ensino superior privado.

Quadro 6. Clusters por instituição de ensino superior

\begin{tabular}{ccccccc}
\hline & & & \multicolumn{4}{c}{ Média de subescala por tipo de cultura } \\
\cline { 4 - 7 } Instituição & Cluster & N. $^{\text {o }}$ de Casos & Clã & Adhocrática & Burocrática & Mercado \\
\hline \multirow{2}{*}{ Instituto } & CL 1 & 10 & 2,49 & 2,32 & 2,76 & 2,40 \\
Público & CL 2 & 29 & 4,70 & 4,78 & 4,47 & 4,43 \\
& CL 3 & 23 & 3,41 & 3,39 & 3,74 & 3,48 \\
\cline { 2 - 7 } Instituto & CL 1 & 8 & 5,69 & 5,54 & 6,02 & 5,44 \\
Privado & CL 2 & 8 & 2,38 & 2,19 & 3,20 & 3,00 \\
& CL 3 & 36 & 3,89 & 4,27 & 4,31 & 4,40 \\
\hline
\end{tabular}

Na caracterização dos clusters das duas instituições de ensino, verifica-se que os 8 indivíduos do sector privado que pertencem ao cluster com 
maiores índices de cultura são maioritariamente do sexo feminino, possuem, na sua maioria, entre 36 e 50 anos, desempenham funções de cariz administrativo e encontram-se numa classe de antiguidade entre os 16 e os 25 anos.

No caso do ensino superior público, a maioria dos 29 indivíduos que compõem o cluster com valores de cultura superiores apresenta habilitações literárias mais elevadas, possuindo, na sua maioria, o ensino secundário (com 8 casos), seguindo-se dos indivíduos com doutoramento, estando representados neste cluster 6 dos 7 indivíduos inquiridos que possuem este grau académico. Embora possuindo, sobretudo, pessoas a desempenhar funções administrativas, este cluster apresenta-se fortemente representado com indivíduos em funções de direcção/gestão. A classe de antiguidade predominante varia entre os 4 e os 10 anos e integra indivíduos principalmente do sexo feminino. Deve-se no entanto apelar para o facto de a amostra de inquiridos no instituto de ensino superior público e privado possuir mais indivíduos do sexo feminino do que masculino. Facto que deverá ser tido em conta na análise dos resultados referidos anteriormente.

\section{Discussão}

Os dados revelaram valores médios de cultura superiores na universidade privada, contudo, tal como esperado nas hipóteses, as diferenças significativas reflectem-se numa orientação para o Mercado, enquanto padrão de cultura marcadamente assumido no ensino superior privado. Esse facto pode ser interpretado pela adaptação constante face às necessidades do meio, procurando nesse sentido dar resposta à concorrência entre universidades privadas e públicas, à redução do número de alunos (questões sociodemográficas) e ao aumento dos numerus clausus no ensino público. Não dependendo financeiramente do Estado, mas sim da propina dos alunos, as universidades privadas necessitam de activar mecanismos que permitam interagir numa lógica de Mercado e, neste sentido, desenvolver critérios mínimos de sobrevivência. Foi possível identificar, nas várias entrevistas efectuadas no instituto privado, que todo um conjunto de estratégias está a ser desenvolvido para optimizar os indicadores de qualidade e produtividade dos seus recursos humanos, características que, segundo Quinn e McGrath (1985), distinguem as culturas de Mercado.

Algumas respostas a essa cultura de Mercado fazem-se sentir nas medidas de aproximação dos alunos à universidade, com especial ênfase na relação existente entre professores e alunos. Da mesma forma, há uma tentativa de criar novos cursos, adequados à necessidade do Mercado. Igualmente, procuram-se ajustes nos curricula de alguns cursos, como forma de torná-los mais adequados às exigências do Mercado. Ao nível do pessoal não docente, prétende-se modernizar os esquemas de gestão de carreiras, com a implementação 
da avaliação de desempenho. Há ainda uma clara aposta nas infra-estruturas, no fundo, procurando modernizar a universidade e redefinir alguns critérios de qualidade que correspondam às expectativas dos seus clientes.

No instituto superior público, também é possível encontrar respostas que vão no sentido do Mercado e da envolvente. A história desta instituição demonstra uma evolução crescente do número de cursos, revelando um claro enfoque no desenvolvimento de novos cursos e adaptação dos existentes às necessidades do meio socioprofissional. Há, nesse âmbito, alguma flexibilidade na criação de secções e departamentos "pivot" de apoio aos diversos cursos existentes. Tenta-se edificar um conjunto de sinergias entre departamentos, docentes, funcionários, como forma de dar uma reposta às necessidades da envolvente. Na mesma linha da universidade privada, procura-se ainda o fomento de parcerias com instituições externas e, desta forma, estender o eixo de actuação das universidades para fora dos muros da academia. De igual forma, assistiu-se, ao longo dos anos, a um forte investimento na modernização das infra-estruturas existentes.

O estudo revela ainda a forte preocupação burocrática, com referência às regras e padrões de comunicação formais, enquanto elementos de distinção entre a universidade privada e a pública. A universidade privada, mais implicada nos valores tradicionais, revela uma maior propensão para culturas burocráticas $(p<0,05)$, facto que aparece suportado numa cultura-base de Clã que recorre às regras e ao controlo para convergir os processos de decisão na figura dos seus líderes. Ao longo das entrevistas, foi possível verificar uma tipologia de cultura de Gestão, com o poder fortemente centralizado na figura dos líderes (Bergquist, 1992). Houve a necessidade de criar uma estrutura de raiz assente num conjunto de regras e de procedimentos que regulassem todo o funcionamento da universidade. Essas normas de cariz burocrático seguem o padrão das estruturas de burocracia prófissional, sugeridas por Mintzberg (1995), e que, sendo muito burocráticas, apresentam estandardização ao nível dos processos. Uma vez que a universidade em causa assistiu a um crescimento bastante acentuado do seu número de alunos, sentiu necessidade de desenvolver uma estrutura que regulasse as mudanças e as alterações que iam sendo impostas pela envolvente. Esta matriz foi sendo desenvolvida ao longo dos anos pelos seus fundadores, inserindo-se no mesmo eixo da cultura de Mercado, com enfoque na previsibilidade, controlo e procura de centralização e integração (Quinn, 1991). Há uma tentativa de perpetuar a tradição e as medidas assumidas enquanto factores de controlo, dando sentido a uma política de continuidade e de reforço da hierarquia, como, aliás, se pode constatar na atribuição dos títulos académicos e no modo de apresentação formal dos seus docentes.

$\mathrm{Na}$ instituição de ensino superior público, a cultura Burocrática apenas se assume na dependência financeira e administrativa com o Estado. A im- 
posição de regras e procedimentos não se coadunam, de todo, com a cultura deste instituto. Na realidade, a cultura Burocrática reflecte-se naquilo que caracteriza a função pública, nomeadamente, a ausência da avaliação de desempenho, segurança e estabilidade contratual, com a inexistência de instrumentos para dissuadir e punir os maus desempenhos. A própria remuneração, de acordo com a tabela e a antiguidade, demonstra um padrão de burocracia tão marcadamente vincado nas empresas do sector público. A aversão às regras e normas pode ser compreendida pela aproximação deste instituto a uma cultura do tipo Clã, facto então evidenciado na análise discriminante. Esta medida foi interpretada pela forma informal com que os diversos agentes escolares interagem entre si. A cultura de Clã tem então a sua génese (tal como na universidade privada) na aproximação dos funcionários face às dificuldades com que se deparavam na altura da fundação. Houve um padrão de grande informalidade, pautado por relações de grande próximidade que uniu as pessoas umas às outras, face a um objectivo comum. Com o crescimento e a departamentalização do instituto, assiste-se a um certo esbatimento desta cultura do tipo familiar. Contudo, a matriz permanece a mesma e permitiu o emergir de líderes carismáticos, do tipo "mentores", tão característicos deste tipo de cultura (Quinn \& McGrath, 1985). Tal facto conduziu, necessariamente, ao fechamento dos departamentos e secções dentro de si próprias, criando regras e formas de trabalho singulares e informais que se afastam de um tipo de cultura Burocrática.

De acordo com as entrevistas realizadas, verificou-se alguma intenção das chefias de ambas as instituições de ensino superior em evoluir para padrões de flexibilização nos procedimentos e criação/inovação de novos produtos de ensino. É preciso, então, implementar estratégias de convergência face a essas intenções, procurando, assim, desenvolver matrizes culturais consonantes com as intenções evidenciadas ao longo do estudo.

Resta, ainda, referir algumas limitações do estudo, que se prendem com o facto de as duas instituições avaliadas não serem totalmente equivalentes. Por outro lado, pretendia-se abarcar a população dos colaboradores de ambas as instituições estudadas, contudo, por factores não controláveis, apenas se conseguiu obter uma amostra correspondente a 50,8\% dos colaboradores na instituição superior pública e $40,6 \%$ na universidade privada, sugerindo-se, para futuros estudos, amostras mais representativas do universo em questão. $\mathrm{Na}$ universidade privada, embora tenha sido possível entrevistar directores, não foi autorizada a realização de entrevistas aos gestores de topo da universidade, nomeadamente, o reitor, o presidente $\mathrm{e}$ membros do Conselho de Administração.

No que concerne ao questionário aplicado, verifica-se que, após estudo das qualidades métricas do mesmo, este apresenta uma fraca validade de constructo. A análise factorial extrai apenas três dos quatro factores esperados, integrando num único factor a perspectiva Adhocrática e de Clã. Estas 
duas dimensões de cultura, embora estando em posições opostas no eixo de internalidade/externalidade, encontram-se, segundo Quinn e McGrath (1985), no mesmo eixo da dimensão controlabilidade/flexibilidade. Pensa-se que, na adaptação da linguagem utilizada na escala original à realidade universitária, poderá ser difícil distinguir cultura de Clã e de Mercado. Além da adaptação linguística à realidade académica, que nunca fora testada no passado, verifica-se um desconhecimento de estudos de adaptação da escala à população portuguesa. Por questões de âmbito cultural, e no seguimento de estudos realizados por Hofstede (1997), a cultura de um país pode afectar a interpretação dos itens e, consequentemente, alterar as qualidades métricas dos questionários. Sugere-se, para futuros estudos, a aplicação de um instrumento devidamente reformulado que meça as dimensões de cultura de Clã e Adhocracia, enquanto factores distintos. Atendendo a estas limitações metodológicas, seria ainda interessante a replicação do estudo noutras instituições de ensino superior público e privado e consequente testagem e validação dos resultados obtidos nesta investigação.

\section{Agradecimentos}

Agradecemos à Professora Doutora Maria José Chambel pelos comentários de melhoramento propostos, numa análise prévia à entrega do artigo.

\section{Referências}

Ashkanasy, N. M., Broadfoot, L. E. \& Falkus, S. (2000). Questionnaire measures of organizational culture. In N. M. Ashkanasy, C. P. Wilderom \& M. F. Peterson (Eds.), Handbook of organizational culture \& climate (pp. 131-145). Thousand Oaks: Sage Publications, Inc.

Bardin, L. (2004). Análise de conteúdo. Lisboa: Edições 70.

Bergquist, W. H. (1992). The four cultures of the academy. San Francisco: Jossey-Bass Publishers, Inc.

Bollinger, D. \& Hofstede, G. (1987). Les différences culturelles dans le management: comment chaque pays gère-t-il ses hommes. Paris: Les Éitions D'organisation.

Cameron, K. S. \& Quinn, R. E. (1999). Diagnosing and changing organizational culture. New York: Addison-Wesley.

Cardoso, L. (2001). Gestão estratégica das organizações: como vencer os desafios do século XXI. Lisboa: Verbo.

Chorão, F. (1992). Cultura organizacional: um paradigma de análise da realidade escolar. Lisboa: Gabinete de estudos e planeamento/Ministério da Educação.

Claudino, S. (1995). Ensino superior português, diplomados e desenvolvimento regional. Lisboa: Centro de Estudos Geográficos. 
Correia, F., Amaral, A. \& Magalhães, A. (2002). Diversificação e diversidade dos sistemas de ensino superior: o caso português. Lisboa: Conselho Nacional de Educação.

Corsini, R. J. (1999). The dictionary of psychology. Philadelphia, PA: Taylor \& Francis.

Denison, D. R. (1990). Corporate culture and organizational effectiveness. New York: John Wiley \& Sons.

Dill, D. (1997). Higher education markets and public policy. Higher Education Policy, 10, 167-185.

Firmino, M. B. (2002). Gestão das organizações: conceitos e tendências actuais. Lisboa: Escolar Editora.

Gago, J. M. (1994). Prospectiva do ensino superior em Portugal. Lisboa: Ministério da Educação, Departamento de Programação e Gestão Financeira.

Geiger, R. (1996). Diversification in U.S. higher education: historical patterns and current trends. In V. L. Meek et al. (Eds.), The mockers and mocked: comparative perspective on differentiation, convergence and diversity in higher education (pp. 188-203). Oxford: Pergamon.

Gomes, R. (1993). Cultura de escolas: identidade à procura de argumentos. Revista de Educação, 3, 23-36.

Gomes, D. (2000). Cultura organizacional: comunicação e identidade. Lisboa: Quarteto.

Hofstede, G. (1991). Vivre dans un monde multiculturel: comprendre nos programmations mentales. Paris : Les éditions d'organisation.

Hofstede, G. (1994). Uncommon sense about organizations: case studies and field observations. Thousand Oaks: Sage Publications.

Hofstede, G. (1997). Cultura e organizações. Compreender a nossa programação mental. Lisboa: Edições Sílabo.

Hofstede, G. \& Peterson, M. F. (2000). Culture: national values and organizational practices. In N. M. Ashkanasy, C. P. Wilderom \& M. F. Peterson (Eds.), Handbook of organizational culture \& climate (pp. 401-415). Thousand Oaks: Sage Publications, Inc.

José, L. Q. (1997). Cultura organizacional em estabelecimentos hoteleiros. Tese de mestrado apresentada em Políticas de Desenvolvimento dos Recursos Humanos no ISCTE, Lisboa.

Lopes, A. \& Reto, L. (1990). Identidade da empresa e gestão pela cultura. Lisboa: Edições Sílabo.

Major, D. A. (2000). Effective newcomer socialization into high-performance organizational cultures. In N. M. Ashkanasy, C. P. Wilderom \& M. F. Peterson (Eds.), Handbook of organizational culture \& climate (pp. 355-368). Thousand Oaks: Sage Publications, Inc.

Mintzberg, H. (1995). Estrutura e dinâmica das organizações. Lisboa: Publicações Dom Quixote.

Neves, J. G. (2000). Clima organizacional, cultura organizacional e gestão de recursos humanos. Lisboa: Editora RH. 
Parker, M. (2000). Organizational culture and identity. London: Sage Publications.

Pesqueux, P. Y. (2003). Les accréditations des cursus de management: Clonage ou amélioration qualitative? Revue Française de Gestion, 29, 147, 201-211.

Peters, T. \& Waterman, R. (1982). In search of excellence. New York: Harper \& Row.

Pheysey, D. C. (1993). Organizational cultures. London: Routledge.

Quinn, R. E. (1988). Beyond rational management. San Francisco: Jossey-Bass Inc. Publishers.

Quinn, R. E. (1991). Beyond rational management: mastering the paradoxes and competing demands of high performance. San Francisco: Jossey-Bass Inc. Publishers.

Quinn, R. E. \& McGrath, M. R. (1985). The transformation of organizational cultures: A competing values perspective. In P. J. Frost, L. F. Moore, M. R. Louis, C. C. Lundberg \& J. Martin (Eds.), Organizational culture (pp. 315-334). Beverly Hills: Sage Publications, Inc.

Ramos, A. S. (1993). Cultura organizacional e estratégia empresarial: um caso de aplicação. Tese de mestrado em Ciências Empresariais no ISCTE, Lisboa.

Sampaio, J. (1991). Autonomia das universidades. Lisboa: Assembleia da República.

Schein, E. H. (1988). Organizational psychology (3rd Edition). Englewood Cliffs: Prentice-Hall, Inc.

Schein, E. H. (1992). Organizational culture and leadership (2nd edition). San Francisco: Jossey-Bass Publishers.

Schein, E. H. (1994). Cultures in organizations: three perspectives. Administrative Science Quarterly, 39, 339-343.

Schein, E. H. (1996). Culture: the missing concept in organization studies. Administrative Science Quarterly, 41, 229-241.

Schein, E. H. (1999). The corporate culture. San Francisco: Jossey-Bass Publishers.

Schein, E. H. (2000). Sense and nonsense about culture and climate. In N. M. Ashkanasy, C. P. Wilderom \& M. F. Peterson (Eds.), Handbook of organizational culture \& climate (pp. XXIII-XXX). Thousand Oaks: Sage Publications, Inc.

Serrão, J. V. (1983). História das universidades. Porto: Lello \& Irmão Editores.

Silva, P. F. (1996). Análise do sistema organizacional das universidades novas: semelhanças, diferenças e graus de desenvolvimento. Tese de mestrado em Gestão apresentada no ISCTE, Lisboa.

Torres, L. L. (1997). Cultura organizacional escolar. Oeiras: Celta Editora.

Wilderom, C. P. \& Glunk, U. (2000). Organizational culture and prediction of predictor performance. In N. M. Ashkanasy, C. P. Wilderom \& M. F. Peterson (Eds.), Handbook of organizational culture \& climate (pp. 193-209). Thousand Oaks: Sage Publications, Inc. 